\title{
Neurogenesis in Adult Mammals: Some Progress and Problems
}

\author{
Elizabeth Gould and Charles G. Gross \\ Department of Psychology, Princeton University, Princeton, New Jersey 08544
}

Approximately 40 years after its first report, the addition of neurons to the brains of adult mammals has now been generally accepted. We now know that several endocrine and experiential variables modulate adult neurogenesis. However, several methodological problems in its quantitative study remain. One is the use of low doses of the exogenous marker of cell proliferation, bromodeoxyuridine (BrdU). A second is the transient lifetime of most of the adult-generated cells. A third is that the survival of new neurons may depend on stimuli that are lacking in standard laboratory conditions. This review considers these issues as well as the possible functions of new neurons.

From the beginnings of modern neuroscience in the late 19th century, it was assumed that the mammalian CNS became structurally stable soon after birth and remained that way throughout life. A fundamental aspect of this stability was that no new neurons were added to the brain in adulthood (Gross, 2000). In the 1960 s, studies using the newly introduced methods of ${ }^{3} \mathrm{H}$ thymidine autoradiography challenged this view. ${ }^{3} \mathrm{H}$-thymidine is taken up by cells undergoing DNA synthesis in preparation for mitosis, and thus can be used as a marker for proliferating cells (at short survival times) and their progeny (at longer survival times). Using this method, Altman (1962, 1963, 1966, 1967, 1969) and Altman and Das $(1965,1966)$ reported new neurons in a variety of structures in the adult rat and cat including the olfactory bulb, hippocampus, and cerebral cortex. Fifteen years later, Kaplan examined the ultrastructure of ${ }^{3} \mathrm{H}$-thymidine-labeled cells in the olfactory bulb, hippocampus, and neocortex of adult rats and confirmed that they were neurons (Kaplan and Hinds, 1977; Kaplan, 1981, 1985; Kaplan and Bell, 1984). Further support that the cells added to the dentate gyrus were neurons came from studies by Stanfield and Trice (1988) and Guéneau et al. (1982). Overall, the pioneering work of these investigators was greeted with considerable skepticism and had little impact on the field (Gross, 2000; Kaplan, 2001). In contrast, demonstrations of adult neurogenesis in nonmammalian vertebrates such as fish, reptiles, and birds appear to have been more readily accepted (Anderson and Waxman, 1985; Nottebohm, 1985, 1989; Lopez-Garcia et al., 1988), but their potential relevance to mammals was not generally acknowledged.

A major source of difficulty in early adult neurogenesis studies was uncertainty whether the adult-generated cells were glia or neurons. Recent evidence suggests that these categories may not be as fixed as previously believed. In the adult brain, some glia may be a source of neurons, and some progenitors give rise to both neurons and glia (Alvarez-Buylla et al., 2001). In fact, recent evidence in the adult rat indicates that the new granule neurons arise from cells with glial characteristics (Seri et al., 2001). In

We thank H. A. Cameron, P. Tanapat, and W. T. Clark for help and the James S. McDonnell Foundation and National Institutes of Health for support.

Correspondence should be addressed to Elizabeth Gould, Department of Psychology, Princeton University, Princeton, NJ 08544. E-mail: goulde@princeton.edu. Copyright (ㄷ) 2002 Society for Neuroscience $0270-6474 / 02 / 220619-05 \$ 15.00 / 0$ addition, the growing evidence that glia communicate among themselves electrically and have many functional properties that interact and overlap with neurons (Rose and Konnerth, 2001; Bezzi and Volterra, 2001) suggests that new glia may play a significant role.

In the 1990s there were several developments that finally established neurogenesis in the adult rodent. The first was the introduction of cell type-specific markers for immunohistochemical identification of the phenotype of newly generated cells (Cameron et al., 1993; Okano et al., 1993; Seki and Arai, 1993). These could be combined with ${ }^{3} \mathrm{H}$-thymidine labeling to determine the identity of the new cells. The second was the introduction of the thymidine analog BrdU as another in vivo marker of proliferating cells (Miller and Nowakowski, 1988; Seki and Arai 1995; Kuhn et al., 1996). An advantage of BrdU is that it can be visualized with immunocytochemical techniques and quantitatively assessed with stereological counting techniques. Furthermore, confocal microscopy can be used to show unequivocal double labeling with BrdU and cell type-specific markers when the cells are rotated in orthogonal planes (Fig. 1). With these techniques, several laboratories confirmed that new neurons are added to the granule cell layer of the dentate gyrus of adult rodents (Cameron et al., 1993; Seki and Arai, 1993; Kuhn et al., 1996). In addition, adult neurogenesis was found in the dentate gyrus of tree shrews, marmoset monkeys, macaque monkeys, and humans (Gould et al., 1997, 1998, 1999b; Eriksson et al., 1998; Kornack and Rakic, 1999). In the dentate gyrus of both rodents and monkeys, adult-generated cells appear to arise from progenitor cells in the hilus or subgranular zone and migrate the short distance to the granule cell layer where they differentiate into neurons.

Recently, we have found new cells with neuronal characteristics in the neocortex of adult rats and macaques, consistent with the earlier claims of Altman (1963) and Kaplan (1981). In the monkey, these adult-generated cells were found in prefrontal cortex, temporal cortex, and parietal cortex (Gould et al., 1999c, 2001; Bedard et al., 2001). The density of adult generated cells with neuronal characteristics is much lower in cortical areas than in the dentate gyrus in both the monkey and the rat (Gould et al., 2001). The site of origin of adult-generated cells in the neocortex is unclear. One possibility is the subventricular zone (SVZ), which is the source of new olfactory bulb neurons in the adult rodent and monkey (Luskin, 1993; Bernier and Parent, 1998; Kornack and Rakic, 2001a). In the macaque we observed adult-generated cells in the white matter that may have been immature neurons migrating from the SVZ to the cerebral cortex. New cortical cells may also arise from local division of progenitors or from progenitors in the white matter (Gould et al., 2001)

\section{Methodological problems with BrdU labeling}

The BrdU technique for in vivo labeling of new cells in the brain was first applied to developing animals (Miller and Nowakowski, 1988; Takahashi et al., 1992). The techniques used in these studies 

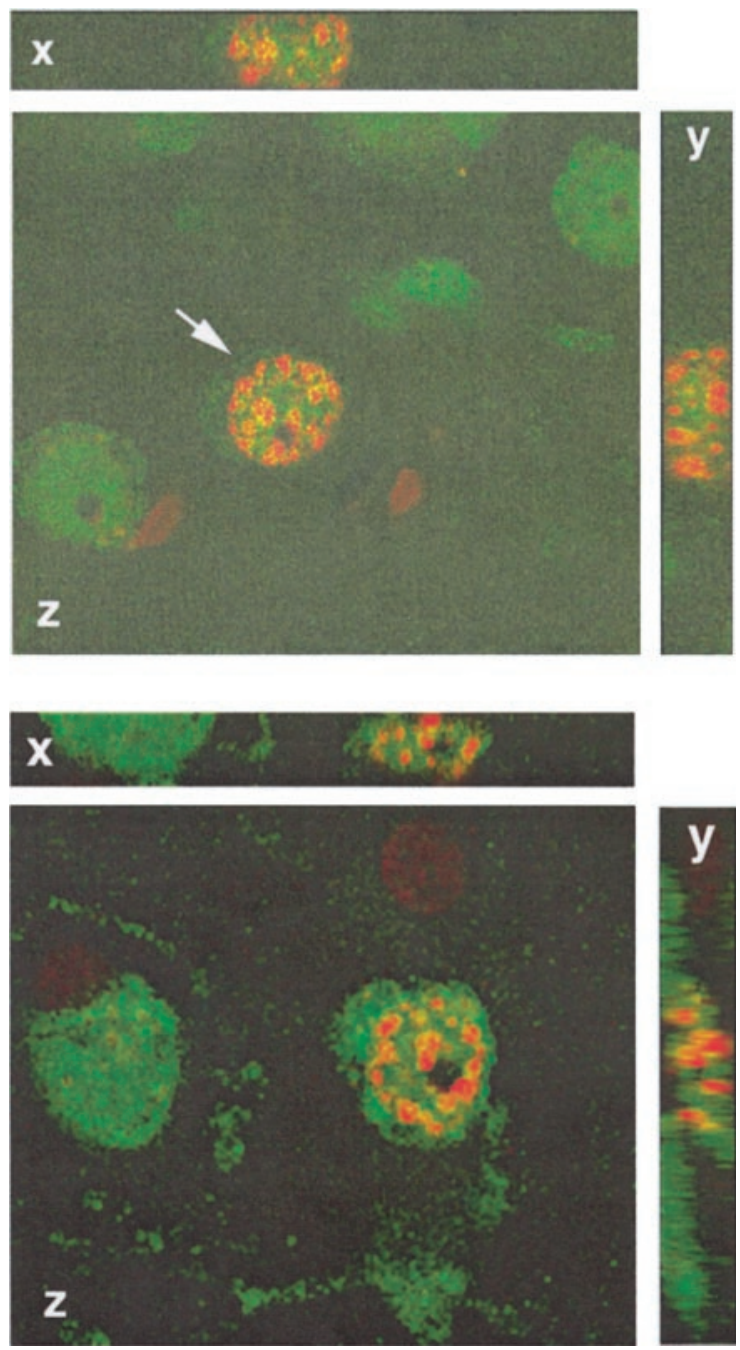

Figure 1. Some new cells in the adult rodent and primate brain have neuronal characteristics. Top panel, Confocal image of a cell (arrow) in the anterior cortex of an adult rat double-labeled with NeuN (green nuclear and cytoplasmic stain; a marker for mature neurons) and BrdU (red nuclear stain; a marker of DNA synthesis). The image is rotated in orthogonal planes $(x, y, z)$ to verify double labeling throughout its extent. The rat was perfused 3 weeks after the BrdU injection. Bottom panel, Confocal image of a cell (arrow) in prefrontal cortex of an adult macaque double-labeled with NeuN ( green) and BrdU (red). The image is rotated in orthogonal planes $(x, y, z)$ to verify double labeling throughout its extent. The monkey was perfused 2 weeks after the BrdU injection (adapted from Gould et al., 2001).

were then assumed to be applicable to studies of the adult brain. For example, it was assumed that BrdU would label all dividing cells in the brain at low doses and would be toxic or label nonspecifically when applied at high doses. Recently, Cameron and McKay (2001) have shown that none of these assumptions applies to adult rats. They showed that the most commonly used dose $(50 \mathrm{mg} / \mathrm{kg})$ labels only a fraction of the cells in S phase in the dentate gyrus at a given time. A plateau in the number of labeled cells was not reached until the dose of $300 \mathrm{mg} / \mathrm{kg}$ was used (Fig. 2). Furthermore, doses as high as $600 \mathrm{mg} / \mathrm{kg}$ did not label spuriously and had no discernible deleterious effects in adults. This suggests that $\mathrm{BrdU}$ and, perhaps ${ }^{3} \mathrm{H}$-thymidine, get into the brain less efficiently in adult animals than in fetuses possibly because of differences in blood flow, metabolism, and the development of the blood-brain barrier.
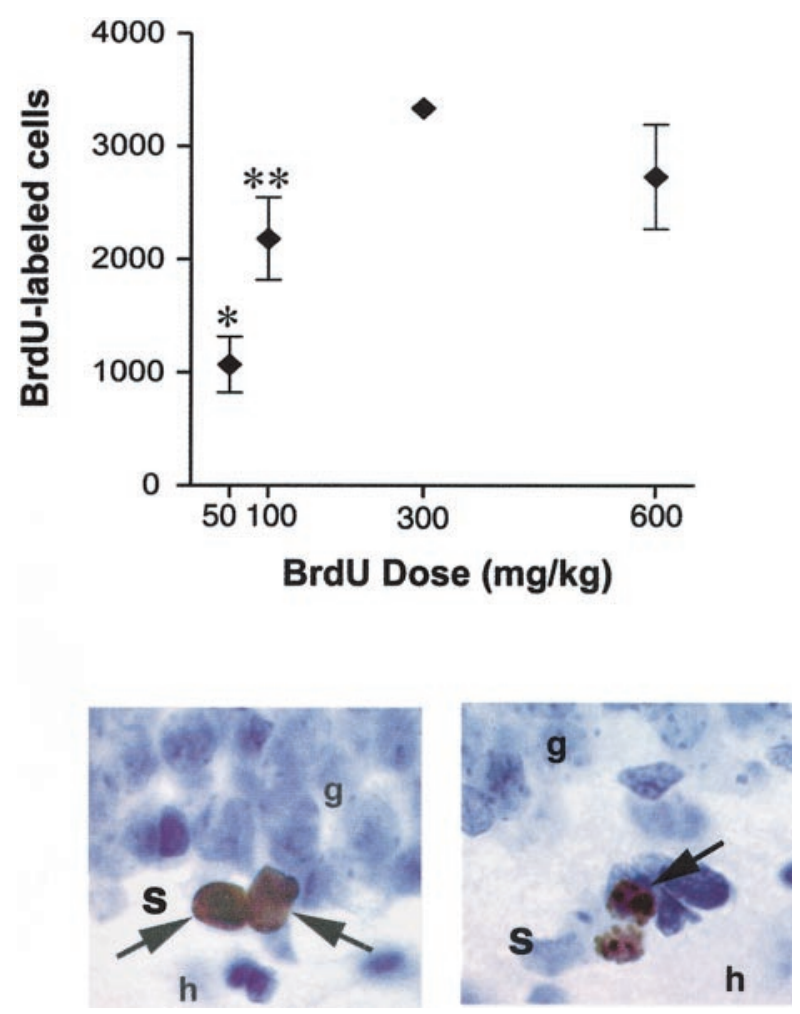

Figure 2. Methodological considerations related to BrdU labeling in adults. Top panel, A short pulse of BrdU labels in a dose-dependent manner, raising the possibility that changes in the number of BrdUlabeled cells could result from differences in BrdU availability. The graph shows the total number of BrdU-labeled cells in the dentate gyrus of adult rats after a single injection of BrdU 30 min earlier. * Indicates significant difference from all other groups, $p<0.05$. **Indicates significant difference from $300 \mathrm{mg} / \mathrm{kg}$ group, $p<0.05$. Adapted from Cameron and McKay (2001) with permission. Bottom panel, Left, BrdU-labeled progenitor cells in the subgranular zone $(s)$ of the dentate gyrus. BrdU is an exogenous marker of proliferating cells. Right, Dividing cell undergoing cytokinesis labeled with phosphorylated histone $\mathrm{H} 3$ in the subgranular zone. $\mathrm{p}$ histone $\mathrm{H} 3$ is an endogenous marker of cells in M phase (Hendzel et al., 1997). Endogenous markers can be used to verify that changes in the number of BrdU-labeled cells are attributable to differences in the number of dividing cells, as opposed to difference in BrdU availability. $g$, Granule cell layer; $h$, hilus.

There are several implications of these findings. The first is that most previous studies of adult neurogenesis have underestimated the number of adult-generated cells. Thus, using higher doses of BrdU, Cameron and McKay (2001) found that $\sim 9000$ progenitor cells exist in the dentate gyrus that have a cell cycle time of $\sim 24$ hr, yielding $\sim 9000$ new cells every day, most of which have the immunocytochemical characteristics of neurons. They calculate that over 270,000 new cells are generated in the dentate gyrus of the adult rat every month. This is remarkable, considering the fact that estimates of total granule cell number in the dentate gyrus have ranged from 1.0-2.0 million in the adult rat (Boss et al., 1985).

The second implication is that low doses of BrdU may result in an inability to detect neurogenesis in certain brain regions (Kornack and Rakic, 2001b). This may be compounded by immunohistochemical methods that lack adequate sensitivity.

The third implication of the customary use of low doses of BrdU is that some of the manipulations reported to modulate adult neurogenesis may change the number of BrdU-labeled cells, not by affecting cell production, but by altering the rate 
of uptake of BrdU. This could occur as a result of changes in blood flow or blood-brain barrier permeability. This is a potential confound with any experimental manipulation that might affect these parameters, such as seizures, exercise, stress, hormone manipulations, and use of anesthetics (Carpentier et al., 1990; Endo et al., 1997, 1999; Delp et al., 2001; Tillfors et al., 2001). Moreover, species or strain differences in the number of BrdU-labeled cells could be explained by differences in BrdU availability unless appropriate controls are performed. For these reasons, doses of BrdU higher than those commonly used in the past should be used for studies that assess cell proliferation. However, even this may not be adequate, particularly when an experimental manipulation results in diminished blood flow. Verification that a change in the number of BrdU-labeled cells is not caused by a change in BrdU availability could be obtained by using an endogenous marker of cell proliferation such as phosphorylated histone H3 (Hendzel et al., 1997) (Fig. 2) and by examining multiple brain regions to verify the specificity of any changes in BrdU labeling.

Because the total number of neurons in the adult brain does not dramatically increase, adult neurogenesis must be accompanied by cell death. The presence of pyknotic cells in the regions that add new neurons provides evidence that this is the case (Gould et al., 2001). There is reason to believe that this degeneration predominantly represents turnover of the adultgenerated population, instead of death of older cells produced during development. In rats the number of adult-generated cells in the dentate gyrus declines markedly between 1 and 2 weeks after their birth; this decline appears to be caused by cell death rather than label dilution (Cameron et al., 1993; Gould et al., 1999a). In the monkey, there is a similar decline after 5 weeks in the dentate gyrus and after 2 weeks in cortex (Gould et al., 2001).

As described below, recent studies have suggested that the unnatural conditions under which standard laboratory animals are housed may decrease the survival of new neurons. Thus, the normal longevity of adult-generated neurons has probably been underestimated by studying animals kept in relatively deprived conditions. These results have important implications for reviewing the existing studies on adult neurogenesis; long survival times after BrdU injection may result in failure to find adultgenerated cells if they surpass the life span of most new cells.

\section{Modulation of hippocampal neurogenesis}

\section{Experience}

Several studies have now shown that enriched environment living, either in the wild or in a laboratory-designed relatively complex environment, enhances the survival of newly generated cells in the hippocampus (Barnea and Nottebohm, 1994; Kempermann et al., 1997, 1998; Nilsson et al., 1999). That is, animals living in standard laboratory conditions lose more new cells than those living in relatively complex environments. These findings imply that data related to the number, regulation, and longevity of newly generated cells must be interpreted in light of the manner in which animals are housed. Relatively impoverished environments may also account for detecting low numbers of new neurons in some regions or inability to find new neurons in some areas.

Exposure to stressful experiences decreases the numbers of new neurons in the dentate gyrus; this occurs not by altering the survival of new cells but by downregulating cell proliferation. Predator odor exposure in adult rats and social stress in tree shrews and marmosets inhibit the proliferation of granule cell precursors in the dentate gyrus (Gould et al., 1997, 1998; Tanapat et al., 2001). This effect appears to be region-specific because no change in BrdU-labeled cells was observed in the SVZ after stress. Some evidence suggests that the stressinduced decrease in granule cell genesis is not just an adult phenomenon; exposure of rat pups to the odors of unfamiliar adult male rats (their natural predators) decreases the number of proliferating cells in the dentate gyrus during the first week of life (Tanapat et al., 1998). Moreover, developmental stress can permanently alter the production of new neurons, that is, the effect continues into adulthood. Studies in rats have shown that prenatal stress persistently dampens the proliferation of granule cell precursors, possibly because of alterations in the hypothalamic pituitary adrenal axis (HPA) (Lemaire et al., 2000). Collectively, these studies demonstrate a general phenomenon of stress-induced activation of the HPA axis that decreases cell production in the dentate gyrus. Recent studies have shown that these decreases in the number of new cells do not last in adult animals living in standard laboratory conditions; the difference between stress and control rats in the number of BrdUlabeled cells is lost between 1 and 3 weeks after BrdU labeling (Tanapat et al., 2001). This phenomenon appears to be attributable to substantial death of the adult-generated population in the control animals, possibly reflecting the deprived living conditions of laboratory animals discussed above.

\section{Hormones}

Cell proliferation in the dentate gyrus is decreased by glucocorticoids, which are released in response to stress, suggesting that stress-induced inhibition of cell proliferation is mediated by glucocorticoids. A recent study indicates this is the case; normalizing glucocorticoid levels (by adrenalectomy and low dose replacement) prevents predator odor stress from inhibiting cell production (Tanapat et al., 2001).

In the absence of stress, treatment with corticosterone, the primary rat glucocorticoid, decreases the number of new cells in the dentate gyrus. Conversely, removal of adrenal steroids by adrenalectomy increases the proliferation of granule cell precursors and, ultimately, the production of immature granule neurons (Cameron and Gould, 1994; Cameron and McKay, 1999). The inhibition of granule cell genesis by these hormones occurs not only in times of stress, but also in response to the natural changes in glucocorticoids across the life span. During the early postnatal period, rats undergo a stress hyporesponsive period during which the levels of circulating glucocorticoids are low and relatively resistant to increasing under conditions of stress (Sapolsky and Meaney, 1986). This period is associated with maximal neurogenesis in the dentate gyrus (Schlessinger et al., 1975; Bayer, 1980). In aged animals, glucocorticoid levels naturally rise (Sapolsky, 1992) coincident with a decrease in the number of newly generated cells (Seki and Arai, 1995; Kuhn et al., 1996; Cameron and McKay, 1999). These findings are, perhaps not surprising, given the catabolic nature of glucocorticoids. However, the effects appear to be specific to the hippocampus, arguing against a general growth-inhibiting effect of glucocorticoids.

In contrast to the inhibitory effects of glucocorticoids on progenitor cells, ovarian steroids have a stimulatory effect on the proliferation of granule cell precursors. Ovarian steroids increase the proliferation of granule cell precursors in the dentate gyrus (Tanapat et al., 1999; Ormerod and Galea, 2001; Daszuta et al., 2001). Experimental manipulation of ovarian hormones by removal of the ovaries and replacement with hormones has demonstrated that estrogen stimulates the production of new granule cells. Endogenous estrogens also mediate new cell production, as shown by the change in rate of granule cell production across the estrous cycle (Tanapat et al., 1999). 
There are two aspects of these estrogen studies that should be noted. First, the additional new cells produced in proestrus are lost over time in animals housed under standard laboratory cage conditions (Tanapat et al., 1999). Second, although the significance of the estrogen-induced increase is not entirely clear, this also may be related to differences between wild and laboratory animals. Continual estrous cycles are not a normal characteristic of rodents living in the wild. The more typical hormone profile is for animals to experience single estrous cycles followed by pregnancy and lactation. Thus, it is more likely that estrogen-associated increases in granule cell genesis evolved as a mechanism to facilitate hippocampal functions related to pregnancy and parenting, such as increased spatial navigation learning for better foraging.

\section{Special properties of adult-generated neurons}

Although recent estimates suggest that the number of new neurons produced in adulthood is much greater than was thought a short while ago, the rate of neurogenesis in adulthood is still low when compared with the rate during development. If the adultgenerated cells have the same relative influence as those generated in early life, then it is difficult to imagine how they would be important. If, on the other hand, these cells have unique properties that increase their impact relative to more mature neurons, then it is possible that their constant incorporation into the existing circuitry would be important. Some evidence suggests that this is the case. Young granule cells in the adult dentate gyrus appear to exhibit robust LTP that, in contrast to mature granule cells, cannot be inhibited by GABA (Wang et al., 2000; Snyder et al., 2001). In addition to this experimental evidence, reasonable assumptions can be made about immature neurons compared with mature neurons. For instance, it is likely that immature neurons form more new connections in a given period of time than mature neurons. This likelihood indicates that new neurons, because they are structurally plastic, are highly susceptible to changes in the environment and to different life experiences. The unique properties of immature granule cells suggest that adult neurogenesis is important because it results in a continual influx of neurons that are, at least temporarily, immature. This might explain the apparent transient nature of most adultgenerated cells.

Some adult-generated neurons survive in the rat dentate gyrus for at least 8 months (Altman and Das, 1965), in the monkey dentate gyrus and cerebral cortex for at least 12 weeks (Gould et al., 2001), and in the human dentate gyrus for at least 2 years (Eriksson et al., 1998). Perhaps these long-lasting adult-generated cells pass through the immature state and eventually develop properties and functions similar to those of cells that originated during development.

\section{Possible functions of adult-generated neurons}

Now that it has been established that new neurons are in fact added to the adult brain, the question becomes what are their functions. It is likely that they play a role in the normal functions of the areas to which they are added. For example, new cells in the dentate gyrus may play a role in hippocampal modulation of the HPA axis response to stress (Herman et al., 1989). The hippocampus has also been implicated in certain learning and memory functions. As discussed elsewhere, there is evidence that the new hippocampal cells may play a role in such functions (Barnea and Nottebohm, 1994; Gross, 2000). For example, learning has been shown to increase the number of new neurons in the hippocampus by altering cell survival or cell proliferation (Gould et al., 1999a; Lemaire et al., 2000). Running increases both the number of new dentate gyrus cells and performance on a hippocampal-dependent task (van Praag et al., 1999a,b). Moreover, decreasing the number of new granule neurons is correlated with impairment on such a task (Shors et al., 2001).

The rediscovery that new neurons are added to several brain regions of adult primates and other mammals has generated considerable interest in the scientific community and the popular press. Indeed, the number of new cells and its modulation by a variety of factors indicates that adult neurogenesis is a significant phenomenon. As has happened in the past with other advances in basic science, however, there seems to be a great deal of impatience to suggest that this phenomenon will provide answers to a wide array of previously intractable problems. Adult neurogenesis has been offered as a possible key to understanding and even treating such phenomena as depression, Alzheimer's disease, and schizophrenia (Murrell et al., 1996; Brezun and Daszuta, 1999; Arango et al., 2001). It would, of course, be wonderful if further study of adult neurogenesis could shed light on any or all of these CNS conditions, but such hopes right now may be premature. At this point, the general acceptance of adult mammalian neurogenesis after nearly 40 years since its initial suggestion is cause enough for celebration.

\section{REFERENCES}

Altman J (1962) Are new neurons formed in the brains of adult mammals? Science 135:1127-1128.

Altman J (1963) Autoradiographic investigation of cell proliferation in the brains of rats and cats. Postnatal growth and differentiation of the mammalian brain, with implications for a morphological theory of memory. Anat Rec 145:573-591.

Altman J (1966) Autoradiographic and histological studies of postnatal neurogenesis II. A longitudinal investigation of the kinetics, migration and transformation of cells incorporating tritiated thymidine in infant rats, with special reference to postnatal neurogenesis in some brain regions. J Comp Neurol 128:431-474.

Altman J (1967) Postnatal growth and differentiation of the mammalian brain, with implications for a morphological theory of memory. In: The neurosciences, a study program (Quarton GC, Melnechuck T, Schmitt FO, eds) pp 723-743. New York: Rockefeller UP.

Altman J (1969) Autoradiographic and histological studies of postnatal neurogenesis IV. Cell proliferation and migration in the anterior forebrain, with special reference to persisting neurogenesis in the olfactory bulb. J Comp Neurol 137:433-458.

Altman J, Das GD (1965) Autoradiographic and histological evidence of postnatal hippocampal neurogenesis in rats. J Comp Neurol $124: 319-335$

Altman J, Das GD (1966) Autoradiographic and histological studies of postnatal neurogenesis. I. A longitudinal investigation of the kinetics, migration and transformation of cells incorporating tritiated thymidine in neonate rats, with special reference to postnatal neurogenesis in some brain regions. J Comp Neurol 126:337-390.

Alvarez-Buylla A, García-Verdugo JM, Tramontin AD (2001) A unified hypothesis on the lineage of neural stem cells. Nat Rev Neurosci 2:287-293.

Anderson MJ, Waxman SG (1985) Neurogenesis in adult vertebrate spinal cord in situ and in vitro: a new model system. Ann NY Acad Sci 457:213-233.

Arango C, Kirkpatrick B, Koenig J (2001) At issue: stress, hippocampal neuronal turnover, and neuropsychiatric disorders. Schizophr Bull 27:477-480.

Barnea A, Nottebohm F (1994) Seasonal recruitment of hippocampal neurons in adult free-ranging black-capped chickadees. Proc Natl Acad Sci USA 91:11217-11221.

Bayer SA (1980) Development of the hippocampal region in the rat. II. Morphogenesis during embryonic and early postnatal life. J Comp Neurol 190:115-134.

Bedard A, Bernier PJ, Vinet J, Levesque M, Goulet S, Parent A (2001) Neuroblast migratory stream in the temporal lobe of the adult primate. Soc Neurosci Abstr 248:8.

Bernier PJ, Parent A (1998) Bcl-2 protein as a marker of neuronal immaturity in postnatal primate brain. J Neurosci 18:2486-2497.

Bezzi P, Volterra A (2001) A neuron-glia signalling network in the active brain. Curr Opin Neurobiol 11:387-394.

Boss BD, Peterson GM, Cowan WM (1985) On the number of neurons in the dentate gyrus of the rat. Brain Res 338:144-150.

Brezun JM, Daszuta A (1999) Depletion in serotonin decreases neurogenesis in the dentate gyrus and the subventricular zone of adult rats. Neuroscience 89:999-1002. 
Cameron HA, Gould E (1994) Adult neurogenesis is regulated by adrenal steroids in the dentate gyrus. Neuroscience 61:203-209.

Cameron HA, McKay RD (1999) Restoring production of hippocampal neurons in old age. Nat Neurosci 2:894-897.

Cameron HA, McKay RD (2001) Adult neurogenesis produces a large pool of new granule cells in the dentate gyrus. J Comp Neurol 435:406-417.

Cameron HA Woolley CS, McEwen BS, Gould E (1993) Differentiation of newly born neurons and glia in the dentate gyrus of the adult rat. Neuroscience 56:337-344.

Carpentier P, Delamanche IS, Le Bert M, Blanchet G, Bouchaud C (1990) Seizure-related opening of the blood-brain barrier induced by soman: possible correlation with the acute neuropathology observed in poisoned rats. Neurotoxicology 11:493-508.

Daszuta A, Hery M, Banasr M, Hery F, Brezun J (2001) Serotonin mediates estrogen stimulation of adult cell proliferation in the rat dentate gyrus. Soc Neurosci Abstr 141:1.

Delp MD, Armstrong RB, Godfrey DA, Laughlin MH, Ross CD, Wilkerson MK (2001) Exercise increases blood flow to locomotor, vestibular, cardiorespiratory and visual regions of the brain in miniature swine. J Physiol (Lond) 533:849-859.

Endo Y, Nishimura JI, Kobayashi S, Kimura F (1997) Long-term glucocorticoid treatments decrease local cerebral blood flow in the rat hippocampus, in association with histological damage. Neuroscience 79:745-752.

Endo Y, Nishimura JI, Kobayashi S, Kimura F (1999) Chronic stress exposure influences local cerebral blood flow in the rat hippocampus. Neuroscience 93:551-555.

Eriksson PS, Perfilieva E, Bjork-Eriksson T, Alborn AM, Nordborg C, Peterson DA, Gage FH (1998) Neurogenesis in the adult human hippocampus. Nat Med 4:1313-1317.

Gould E, McEwen BS, Tanapat P, Galea LAM, Fuchs E (1997) Neurogenesis in the dentate gyrus of the adult tree shrew is regulated by psychosocial stress and NMDA receptor activation. J Neurosci 17: 2492-2498.

Gould E, Tanapat P, McEwen BS, Flugge G, Fuchs E (1998) Proliferation of granule cell precursors in the dentate gyrus of adult monkeys is diminished by stress. Proc Natl Acad Sci USA 95:3168-3171.

Gould E, Beylin A, Tanapat P, Reeves A, Shors TJ (1999a) Learning enhances adult neurogenesis in the hippocampal formation. Nat Neurosci 2:260-265.

Gould E, Reeves AJ, Fallah M, Tanapat P, Gross CG, Fuchs E (1999b) Hippocampal neurogenesis in Old World primates. Proc Natl Acad Sci USA 96:5263-5267.

Gould E, Reeves AJ, Graziano MSA, Gross CG (1999c) Neurogenesis in the neocortex of adult primates. Science 286:548-552.

Gould E, Vail N, Wagers M, Gross CG (2001) Adult-generated hippocampal and neocortical neurons in macaques have a transient existence. Proc Natl Acad Sci USA 98:10910-10917.

Gross CG (2000) Neurogenesis in the adult brain: death of a dogma. Nat Rev Neurosci 1:67-73.

Guéneau G, Privat A, Drouet J, Court L (1982) Subgranular zone of the dentate gyrus of young rabbits as a secondary matrix. Dev Neurosci 5:345-358.

Hendzel MJ, Wei Y, Mancini MA, Van Hooser A, Ranalli T, Brinkley BR, Bazett-Jones DP, Allis CD (1997) Mitosis-specific phosphorylation of histone $\mathrm{H} 3$ initiates primarily within pericentromeric heterochromatin during G2 and spreads in an ordered fashion coincident with mitotic chromosome condensation. Chromosoma 106:348-360.

Herman JP, Schafer MK, Young EA, Thompson R, Douglass J, Akil H, Watson SJ (1989) Evidence for hippocampal regulation of neuroendocrine neurons of the hypothalamo-pituitary-adrenocortical axis. J Neurosci 9:3072-3082.

Kaplan MS (1981) Neurogenesis in the 3-month-old rat visual cortex. J Comp Neurol 195:323-338.

Kaplan MS (1985) Formation and turnover of neurons in young and senescent animals: an electron microscopic and morphometric analysis. Ann NY Acad Sci 457:173-192.

Kaplan MS, Bell DH (1984) Mitotic neuroblasts in the 9-day-old and 11-month-old rodent hippocampus. J Neurosci 4:1429-1441.

Kaplan MS (2001) Environment complexity stimulates visual cortex neurogenesis: death of a dogma and a research career. Trends Neurosci 24:617-620.

Kaplan MS, Hinds JW (1977) Neurogenesis in the adult rat: electron microscopic analysis of light radioautographs. Science 197:1092-1094.

Kempermann G, Kuhn HG, Gage FH (1997) More hippocampal neurons in adult mice living in an enriched environment. Nature 386:493-495.

Kempermann G, Kuhn HG, Gage FH (1998) Experience-induced neurogenesis in the senescent dentate gyrus. J Neurosci 18:3206-3212.

Kornack DR, Rakic P (1999) Continuation of neurogenesis in the hippocampus of the adult macaque monkey. Proc Natl Acad Sci USA 96:5768-5773.

Kornack DR, Rakic P (2001a) The generation, migration, and differentiation of olfactory neurons in the adult primate brain. Proc Natl Acad Sci USA 98:4752-4757.
Kornack DR, Rakic P (2001b) Cell proliferation without neurogenesis in adult primate neocortex. Science 294:2127-2130.

Kuhn HG, Dickinson-Anson H, Gage FH (1996) Neurogenesis in the dentate gyrus of the adult rat: age-related decrease of neuronal progenitor proliferation. J Neurosci 16:2027-2033.

Lemaire V, Koehl M, Le Moal M, Abrous DN (2000) Prenatal stress produces learning deficits associated with an inhibition of neurogenesis in the hippocampus. Proc Natl Acad Sci USA 97:11032-11037.

Lopez-Garcia C, Molowny A, Garcia-Verdugo JM, Ferrer I (1988) Delayed postnatal neurogenesis in the cerebral cortex of lizards. Brain Res 471:167-174.

Luskin MB (1993) Restricted proliferation and migration of postnatally generated neurons derived from the forebrain subventricular zone Neuron 11:173-189.

Miller MW, Nowakowski RS (1988) Use of bromodeoxyuridineimmunohistochemistry to examine the proliferation, migration and time of origin of cells in the central nervous system. Brain Res 457:44-52.

Murrell W, Bushell GR, Livesey J, McGrath J, MacDonald KP, Bates PR Mackay-Sim A (1996) Neurogenesis in adult human. NeuroReport 7:1189-1194.

Nilsson M, Perfilieva E, Johansson U, Orwar O, Eriksson PS (1999) Enriched environment increases neurogenesis in the adult rat dentate gyrus and improves spatial memory. J Neurobiol 39:569-578.

Nottebohm F (1985) Neuronal replacement in adulthood. Ann NY Acad Sci 457:143-161.

Nottebohm F (1989) From bird song to neurogenesis. Sci Am 260:74-79.

Okano HJ, Pfaff DW, Gibbs RB (1993) RB and Cdc2 expression in brain: correlations with $3 \mathrm{H}$-thymidine incorporation and neurogenesis. J Neurosci 13:2930-2938.

Ormerod BK, Galea LA (2001) Reproductive status influences cell proliferation and cell survival in the dentate gyrus of adult female meadow voles: a possible regulatory role for estradiol. Neuroscience 102:369-379.

Rose CR, Konnerth A (2001) Exciting glial oscillations. Nat Neurosci 4:773-774.

Sapolsky RM (1992) Do glucocorticoid concentrations rise with age in the rat? Neurobiol Aging 13:171-174.

Sapolsky RM, Meaney MJ (1986) Maturation of the adrenocortical stress response: neuroendocrine control mechanisms and the stress hyporesponsive period. Brain Res 396:64-76.

Schlessinger AR, Cowan WM, Gottlieb DI (1975) An autoradiographic study of the time of origin and the pattern of granule cell migration in the dentate gyrus of the rat. J Comp Neurol 159:149-175.

Seki T, Arai Y (1993) Highly polysialylated neural cell adhesion molecule (NCAM-H) is expressed by newly generated granule cells in the dentate gyrus of the adult rat. J Neurosci 13:2351-2358.

Seki T, Arai Y (1995) Age-related production of new granule cells in the adult dentate gyrus. NeuroReport 6:2479-2482.

Seri B, Garcia-Verdugo JM, McEwen BS, Alvarez-Buylla A (2001) Astrocytes give rise to new neurons in the adult mammalian hippocampus. J Neurosci 21:7153-7160.

Shors TJ, Miesegaes G, Beylin A, Zhao M, Rydel T, Gould E (2001) Neurogenesis in the adult is involved in the formation of trace memories. Nature 410:372-376.

Snyder JS, Kee N, Wojtowicz JM (2001) Effects of adult neurogenesis on synaptic plasticity in the rat dentate gyrus. J Neurophysiol 85:2423-2431.

Stanfield BB, Trice JE (1988) Evidence that granule cells generated in the dentate gyrus of adult rats extend axonal projections. Exp Brain Res 72:399-406.

Takahashi T, Nowakowski RS, Caviness Jr VS (1992) BUdR as an S-phase marker for quantitative studies of cytokinetic behaviour in the murine cerebral ventricular zone. J Neurocytol 21:185-197.

Tanapat P, Galea LA, Gould E (1998) Stress inhibits the proliferation of granule cell precursors in the developing dentate gyrus. Int J Dev Neurosci 16:235-239.

Tanapat P, Hastings NB, Reeves AJ, Gould E (1999) Estrogen stimulates a transient increase in the number of new neurons in the dentate gyrus of the adult female rat. J Neurosci 19:5792-5801.

Tanapat P, Hastings NB, Rydel TA, Galea LA, Gould E (2001) Exposure to fox odor inhibits cell proliferation in the hippocampus of adult rats via an adrenal hormone-dependent mechanism. J Comp Neurol 437:496-504.

Tillfors M, Furmark T, Marteinsdottir I, Fischer H, Pissiota A, Langstrom B, Fredrikson M (2001) Cerebral blood flow in subjects with social phobia during stressful speaking tasks: a PET study. Am J Psychiatry 158:1220-1226.

van Praag H, Christie BR, Sejnowski TJ, Gage FH (1999a) Running enhances neurogenesis, learning and long-term potentiation in mice. Proc Natl Acad Sci USA 96:13427-13431.

van Praag H, Kempermann G, Gage FH (1999b) Running increases cell proliferation and neurogenesis in the adult mouse dentate gyrus. Nat Neurosci 2:266-270.

Wang S, Scott BW, Wojtowicz JM (2000) Heterogenous properties of dentate granule neurons in the adult rat. J Neurobiol 42:248-257. 